\title{
New Genetic Mutation in a Patient with Charcot-Marie-Tooth Disease
}

\author{
Francisco Javier Domínguez Díez* and José Tomás López Alburquerque \\ Hospital Universitario de Salamanca, Salamanca, Salamanca Spain \\ *Corresponding author: Díez FJD, Hospital Universitario de Salamanca, Neurology Paseo de San Vicente 58 Salamanca, Salamanca 37007 , Spain, Tel: \\ 0034628784540; Fax: 628784540; E-mail: javierdominguezdiez@gmail.com
}

Received date: April 20, 2017; Accepted date: May 11, 2017; Published date: May 19, 2017

Copyright: ( 2017 Díez FJD, et al. This is an open-access article distributed under the terms of the Creative Commons Attribution License, which permits unrestricted use, distribution and reproduction in any medium, provided the original author and source are credited.

Citation: Díez FJD, Alburquerque JTL (2017) New Genetic Mutation in a Patient with Charcot-Marie-Tooth Disease. Biol Syst Open Access 6: 180. doi: $10.4172 / 2329-6577.1000180$

\section{Short Communication}

We present the case of a patient affected by Charcot-Marie-Tooth (CMT) disease with a mutation which has not yet been described.

The patient is a 39 year old man who was diagnosed during childhood with CMT disease type 1 . His mother suffers from the same condition, with mild clinical involvement. His father and sister are healthy.

At the end of his adolescence, the patient already presented with significant distal amyotrophy in hands and feet, with weakness, claw hand, high arch and difficulty to walk on tiptoe or heels, with steppage gait. He shows general areflexia and slight tactile hypoesthesia and distal hypopallesthesia. The physical examination results have not shown significant changes over the last years. Neurophysiological studies have always revealed a decrease in conduction velocity and in the amplitude of motor evoked potentials (last study: 2013, with $21 \mathrm{~m} / \mathrm{s}$ and $0.2 \mathrm{mV}$ in the median nerve and $23.9 \mathrm{~m} / \mathrm{s}$ and $0.3 \mathrm{mV}$ in the ulnar nerve), associated to an impossibility to evoke the sensory and the somatosensory potentials. The patient shows severe manipulatory disability and disability of walking, and he is currently trying to have children.

In 2013, it was decided to carry out a genetic study. With a multistage procedure, genotyping was first carried out by polymerase chain reaction and oligo-allele specific extension of a series of polymorphisms distributed along the CMT1/HNPP (17p11.2) region, without any evidence of duplication or deletion. Afterwards, a massive sequencing of 7 genes was carried out from the gene panel associated to autosomal dominant CMT disease type 1 , and no clearly pathogenic variant associated to the disease was found. Given these results, the study was expanded to include 42 genes and a heterozygous mutation for the SBF1 [c577C>T (pArg193Trp)] was found (mutations in this gene are associated to X-linked autosomal recessive CMT disease [1]), as well as a hemizygous mutation in the GJB1 gene [c.476_481del (pGly159_Tyr160del)] (mutations in this gene are associated to Xlinked dominant CMT disease [1]). Since these were not pathogenic variants clearly associated to CMT disease, a confirmation study with Sanger sequencing and a co-segregation study were performed on the mother, starting with the GJB1 gene, in order to establish whether it was a de novo mutation or it had been inherited.

The studies confirmed the presence of the mutation [c.476_481del (pGly159_Tyr160del)], and also that the mother was a heterozygous carrier. This mutation had never been described in association with Charcot-Marie-Tooth disease [1]. The pattern in this clinical case is Xlinked dominant inheritance.

We describe a new mutation in the GJB1 gene, located in Xq13.1, which encodes for the gap junction beta 1 protein called connexin 32 $[2,3]$, in a case of demyelinating Charcot-Marie-Tooth disease with an $\mathrm{X}$-linked dominant inheritance pattern. The involvement of this gene is the second most common genetic alteration after duplication in chromosome 17p11.2-p12 of the PMP 22 gene $[3,4]$.

Gap junctions allow small molecules to diffuse through myelin sheaths. Consequently, it is posited that mutations in this gene prevent normal cell communication, which in turn leads to a dysfunction in Schwann cell myelination [5].

Strangely enough, in these X-linked inheritance patterns, motor conduction velocity is not homogeneous in the different nerves, and it is not as reduced as in autosomal dominant forms [4,5], such as in our case. On the other hand, some disorders with involvement of the central nervous system are occasionally associated to X-linked patterns [1], and this is the reason why a brain NMR was performed on our patient, with normal results.

Finally, we believe that it is important to characterize and record these alterations, both because of the possibility of genetic counselling (as in our patient) and because of the long-term prognostic and therapeutic implications which it may have, based on future research.

\section{References}

1. Kleopa KA, Scherer SS (2006) Molecular genetics of X-linked CharcotMarie-Tooth disease. Neuromolecular Med 8: 107-122.

2. Pareyson D, Marchesi C (2009) Diagnosis, natural history and management of Charcot-Marie-Tooth disease. Lancet Neurol 8: 654-667.

3. Ouvrier R, Geevasingha N, Ryan MM (2007) Autosomal-recessive and Xlinked forms of hereditary motor and sensory neuropathy in childhood. Muscle Nerve 36: 131-143.

4. Carter GT, Weiss MD, Han JJ, Chance PF, England JD (2008) CharcotMarie-Tooth disease. Curr Treat Options Neurol 10: 94-102.

5. Shy ME, Siskind C, Swan ER (2007) CMT1X phenotypes represent loss of GJB1 gene function. Neurology 68: 849-855. 